Portland State University

PDXScholar

$1-1-2012$

\title{
Interview or Interrogation: a Critical Review of the Efficacy and Ethicality of Post-Conviction Sex Offender Polygraph Testing
}

Arthur J. Nelson

Portland State University

Follow this and additional works at: https://pdxscholar.library.pdx.edu/honorstheses

Let us know how access to this document benefits you.

Recommended Citation

Nelson, Arthur J., "Interview or Interrogation: a Critical Review of the Efficacy and Ethicality of PostConviction Sex Offender Polygraph Testing" (2012). University Honors Theses. Paper 3.

https://doi.org/10.15760/honors.3

This Thesis is brought to you for free and open access. It has been accepted for inclusion in University Honors Theses by an authorized administrator of PDXScholar. Please contact us if we can make this document more accessible: pdxscholar@pdx.edu. 
INTERVIEW OR INTERROGATION

Interview or interrogation:

A critical review of the efficacy and ethicality of post-conviction sex offender polygraph testing.

Arthur J. Nelson

Portland State University

\begin{abstract}
Author Note
Arthur J. Nelson, Student, Portland State University

Correspondence concerning this article should be addressed to Arthur Nelson, Department of Psychology, Portland State University, P.O. Box 751, Portland, Oregon 97207. Email: nelsonaj@pdx.edu
\end{abstract}




\section{INTERVIEW OR INTERROGATION}

\section{Abstract}

Recently the polygraph, despite its scientific dubiousness, has gained popularity across the globe within post-conviction sex offender management programs, even at times being mandated via judicial decree or legislation. Consequently, the application of this controversial device in sex offender rehabilitation has caused much heated, and at times muddled, debate amongst psychologists as to whether the polygraph is effective, or even ethical. This review surveys the current pool of literature concerning the efficacy and ethicality of the practice of post-conviction sex offender polygraph testing in order to give a clearer overview of the published literature, and to point at future directions and gaps in the research. While the psychological literature, as it stands, does offer up some promise in the polygraph's ability to aid rehabilitation (increasing honest responding, positive outlook from offenders, etc.), little in the way of definitive proof exists concerning the polygraph's ability to reduce recidivistic behavior. Additionally, a lack of consensus amongst psychologists, methodological weaknesses and severe gaps in the literature lead to a conclusion that post-conviction sex offender polygraph testing should be limited to a research capacity only, despite increased legislative support. Keywords: polygraph, sex offenders, rehabilitation, post-conviction, intervention 
INTERVIEW OR INTERROGATION

Interview or interrogation:

A critical review of the efficacy and ethicality of post-conviction sex offender polygraph testing.

\section{Introduction}

In the field of forensic psychology, few things are as important as the clear and concise understanding of what is appropriate and necessary in order to answer legal questions through the discipline of psychology. Though there is some inherent conflict within the partnership of the idiographic, philosophical realm of law and the more scientific, nomothetic field of psychology, a level of coordination and functionality is possible. However, when the legal and political communities endorse the utilization of methods and techniques that have not been accepted, or have even been spurned, by the scientific community, a crucial schism arises. In no other situation is this truer than in the approval and mandate of post-conviction polygraph testing. While some psychologists claim that it serves as an excellent tool in the rehabilitation of sex offenders, others argue that it is an unscientific, invalid, and possibly unethical shortcut that should be avoided.

For some forensic psychologists, the management and treatment of sex offenders is a truly difficult, and at times, daunting task. Treatment often includes forcing the offenders to take responsibility for their actions and to break down the cognitive distortions that facilitate the commission of deviant activities. The only problem with treating such a population is that there tends to be a lack of honesty in the admission of past and current behavior. While this information is considered crucial in the treatment of sex offenders, what lengths should the therapists in charge of the management go to obtain the complete truth? Across the globe, legislators, as well as a portion of the 
INTERVIEW OR INTERROGATION

psychological community, have found that turning to the polygraph (also mislabeled the "lie detector" in popular culture) to be a necessary step in the rehabilitation of previously incarcerated sex offenders.

In the United States of America, and increasingly the United Kingdom, the use of the polygraph has become popular, and in many cases, mandatory in the management and treatment of post-conviction sex offenders. For example, in Colorado, released sex offenders are required to adhere to compulsory, periodic polygraph testing (Grubin, 2010). In fact, sex offender management is one of the few instances in a forensic setting in which juvenile offenders have been required to comply with periodic testing (Chafin, 2011).

However, despite its widespread use and the surge in legislation promoting its implementation, there is still much contention surrounding the polygraph test within the scientific community. Most scientists from varying disciplines have condemned the polygraph as invalid, inaccurate, unreliable, and possibly an irresponsible means of attaining the truth (e.g., Furedy, 1996; Ben-Shakhar, 2008; Vess, 2011; Cross, \& Saxe, 2001; Meijer, Verschuere, Merckelbach, \& Crombez, 2008). The scientific community has raised many questions concerning the accuracy and validity of the polygraph itself, and even more questions concerning the ethicality of its application have emerged. Should the polygraph be considered a valid means of attaining honest and complete admissions from sex offenders? Is it ethical to subject sex offenders to repeated tests using a measure that is not generally considered valid by the scientific community on the whole? Many articles have been written on the subject, but little consensus exists within the psychological community as to the answers to these important questions. 
INTERVIEW OR INTERROGATION

The purpose of this review is three fold: to provide a background of the polygraph and its contemporary application in post-conviction sex offender management, to give an overview of the current psychological literature concerning its application within this capacity, and finally, to provide an assessment of the discourse on the practice of postconviction sex offender polygraphy and to predict possible future directions. Through this thorough examination, a schism between the scientific and forensic aspects of forensic psychology will become apparent, as even though there is no scientific agreement concerning the use of the polygraph, governments all over the world are promoting, and even mandating it.

\section{Polygraphy}

Since its very inception in the early 20 th century, the polygraph has been surrounded by controversy and debate as to its validity and accuracy. Though it remains largely misunderstood and misrepresented in the private sector, scientists have reached little consensus as to the validity and accuracy of the polygraph itself. However, as a means of understanding the argument at hand in this review, it is important to first put the polygraph into context concerning its function, and its current application in sex offender management and rehabilitation.

\section{Measures}

The modern polygraph as it is used in today's society typically consists of several different sensors used to record physiological data from those being tested. These physiological responses include respiratory rate, heart rate, blood pressure, and galvanic skin response. During a polygraph interview, the interviewer will present the examinee with various questions, and the physiological responses recorded by the polygraph are 
INTERVIEW OR INTERROGATION

then compared to a "baseline" measurement taken before the exam itself. It is then the task of the interviewer to conclude whether the response elicited from the examinee to the specific questions should be regarded as truthful, deceptive, or inconclusive. Generally, fluctuations in the major physical indicators are associated with various forms of psychological and physiological functioning, i.e., the autonomic nervous system, but for the purposes of the polygraph, they are more specifically used to indicate when an interviewee is being deceptive in response to interview questions.

When it is believed that deception has been detected during the interview, this is referred to as a positive result, whereas a lack of deception is labeled as a negative result, and an ambiguous result is considered inconclusive. Thus, a false positive would be when deception is detected where none existed, and a false negative would be deception that passes undetected by the polygraph.

Critics of the polygraph have pointed out that these physiological patterns are not specific to deception alone, and that any number of emotional responses (such as fear, anger, embarrassment, etc.) could register as a "positive" result (e.g., Ben-Shakhar, 2008). This underlines the general concerns as to the accuracy of the polygraph, as well as the validity of the conclusions drawn by the interviewer from the results. Additionally, opponents also bring up the point that the interpretations of the physiological responses are not standardized, and highly subjective (Ben-Shakhar, 2008; Cross, \& Saxe, 2001).

\section{Testing Methods}

As mentioned above, the interpretation of the results from a polygraph test are based on the comparison of physiological responses from pertinent questions to a collected baseline. Amongst the testing methods used today, two forms seem to persist: 
INTERVIEW OR INTERROGATION

the Guilty Knowledge Test (GKT) and the Control Question Test (CQT), with the latter being the most prevalent (Ben-Shakhar, 2003; Ben-Shakhar, 2008).

The Guilty Knowledge Test consists several pertinent questions, as well as a series of control questions. These control questions are typically similar to the pertinent questions save for a single specific detail that would only be known to a person with specific knowledge of the act. After the test, the interviewer would analyze the interviewee's physiological reactions to the pertinent questions as compared to those of the control, and deception is extrapolated (Ben-Shakhar \& Elaad, 2003). An example of the questions one would ask in a GKT concerning petty theft someone's dresser would be:

- Did you take the money from the cabinet?

- Did you take the money from the dresser drawer?

- Did you take the money from the purse?

For this example, the pertinent question would be about taking the money from the dresser, and the control questions would be concerning the cabinet and the purse.

The other, more common form of testing, is the Control Question Test. Used widely throughout the United States and Europe, the CQT is the most prevalent form of polygraph testing used in sex offender management (Grubin, 2008). Like most forms of polygraphy, the CQT is used to detect deception by comparing the physiological responses of the interviewee when responding to pertinent questions, and questions that are only vaguely relevant (“control”) questions (Grubin, 2008; Ben-Shakhar \& Elaad, 2003). A pertinent question would be one relating directly to the behavior in question (e.g. "Did you assault the victim last night?”). In contrast, a control question would be 
INTERVIEW OR INTERROGATION

related, but much more broad than the pertinent question (e.g. "Have you ever perpetrated violence against another person?").

Between the two common testing forms of the polygraph, the main focus of this review will be on the CQT because, as mentioned above, it is the most common form of polygraph testing used in the post-conviction management and treatment of sex offenders. Additionally, the CQT is the most commonly referred form of psychological testing in current literature on the subject of post-conviction polygraph testing, as will be seen later on in the review.

\section{Prevalence of Post Conviction Polygraph Testing}

While the polygraph has long been seen as controversial, it comes as a surprise that its endorsement through legislation and sex offender treatment programs has become so widespread. As mentioned above, the polygraph has become a mandated element to the treatment and management of sex offenders in many states, such as Colorado, and even Oregon (Grubin, 2008). In fact, it is estimated that here in the United States of America alone, roughly 75 percent of institutional sex offender treatment programs utilize polygraph testing, as well as approximately 80 percent of community based programs (Grubin, 2010).

Alongside its popularity here in the States, the post-conviction polygraph testing of sex offenders has spread overseas as well. In Japan, for example, the use of the GKT has become common in many forensic procedures, not excluding post-conviction applications (Ben-Shkhar, 2003). Additionally, in the United Kingdom, a trial period of mandatory polygraph testing in post-conviction sex offender management was begun in 2009 (Grubin, 2010). These large-scale trial periods began two years following 
INTERVIEW OR INTERROGATION

legislation passed in the country that allowed for the mandate of polygraph testing in the release conditions of certain sex offenders.

\section{Empirical Research}

Contemporary empirical research on the subject of post-conviction sex offender polygraph testing seems to reflect a positive view of the practice, if not at least cautious optimism. Almost every published empirical study so far has been quasi-experimental, utilizing the population of sex offenders available to the researchers. Samples almost exclusively consisted of sex offenders already undergoing community-based treatment, or under some other form of treatment in accordance with parole conditions (e.g. Grubin, 2010; Grubin, Madsen, Parsons, Sosnowski, \& Warberg, 2004; Kokish, Levenson, \& Blasingame, 2005.)

Increasing Honest Disclosures

When treating sex offenders, it is considered paramount by therapists to obtain as complete of a sexual history as possible, as well as to obtain forthright of information concerning behavior that may prove detrimental to rehabilitation (Madsen, Parsons, \& Grubin, 2004; Grubin, Madsen, Parsons, Sosnowski, \& Warburg, 2004). Several research studies have been conducted in the past decade in order to examine the effect of polygraph testing on its ability to produce more candid and complete information from the offenders being interviewed.

On the whole, the polygraph appears to have a marked effect on the quantity of confessions made by sex offenders regarding their past and current behavior. One such study focusing on this subject was conducted by Grubin, Madsen, Pasons, Sosnowski, 
INTERVIEW OR INTERROGATION

and Warberg (2004). In this study, 50 adult male sex offenders undergoing communitybased treatment in the United Kingdom were subjected to polygraph testing, using the CQT, in order to increase their disclosures concerning high-risk behavior. The subjects were split into two groups, those that were told there would be a polygraph examination in three months concerning their behavior during treatment ("polygraph aware"), and a second group that was only informed of the behavioral review, and not the polygraph test ("polygraph unaware"). The procedure originally outlined for a second round of polygraph testing six months after the original interview. Participants who passed the polygraph would be told to expect a simple behavioral review in six months, and those who failed would be reprimanded and then told to expect a second polygraph examination.

The primary measures of this study were the number of confessions to high-risk behavior that were made by the participants. Based on the design of the experiment, the researchers hypothesized that those who were expecting the polygraph test would confess fewer high-risk behaviors than those who were not at both times.

At the first polygraph test, 32 of the original 50 participants who agreed to partake in the study showed up to the examination. Of those that took part in the exam, 31 of the 32 participants admitted to a various high-risk behaviors while under-going treatment $(\mathrm{N}$ $=2.45$ admissions) with no significant difference between the aware and unaware groups. Due to the fact that all but one of the participants had admitted to committing high-risk behaviors while under treatment, all participants were informed of an impending polygraph exam. When tested for a second time, only 21 participants attended. Among those who remained in the study, 15 participants reported an average of 1.6 high-risk 
INTERVIEW OR INTERROGATION

behaviors, and six participants reported no high-risk behaviors at all. It was noted that these participants passed their polygraph test. Following the exams, a questionnaire was given to the subjects, on which 20 of the participants indicated that they found the polygraph helpful in avoiding the commission of another offense, and 12 reported that knowing they would be subject to polygraph testing aided them in avoiding high risk behavior. It is worth noting, however, that these are the same participants who were involved in the study to its completion, and thus can be assumed to have been the most interested/optimistic about the practice.

Grubin et al. (2004) concluded that not only did the polygraph increase the rate at which offenders reported acts of high-risk behavior to their supervisors, but also that it helped them avoid recidivating so long as the offender was motivated to complete treatment. A few of the limitations on the results of this research that were discussed concerned the possibility that sex offenders confessed to high-risk behavior in order to appease their supervisors, and that the decreased failure rate on the second round of testing was a result of the implementation of countermeasures. Though these limitations warrant consideration, the researchers noted them as being unlikely. However, its most glaring limitation is the study's relatively low sample size and high dropout rate. Not only does this compromise the integrity of the results gathered from the study, but also limits the extent to which the conclusions drawn by the researchers can be generalized.

Though getting more information from offenders is considered important, it begs to wonder whether these confessed behaviors are crucial enough to warrant such extreme measures. After all, if the confessed behaviors were fairly minor in nature, then the importance of knowing them would barely warrant such controversial methods of 
INTERVIEW OR INTERROGATION

interviewing. If, however, the polygraph brought forth information of past deviant behavior that is considered serious enough, the procedure could be viewed with a fair bit more significance. As it would appear, post-conviction sex offender polygraph testing seems to not only increases the frequency of confessions to high-risk behavior, but also extracts more serious behavior that was previously unknown.

A study published that same year as Grubin et al. (2004) sought to specifically test the effect of post-conviction polygraph testing on the seriousness of the behaviors disclosed by sex offenders undergoing treatment (Madsen, Parsons, \& Grubin, 2004). Despite the controversies surrounding the accuracy of the polygraph test, it was hypothesized that when exposed to repeat polygraph exams, both the quantity and severity of the high-risk behaviors disclosed by the offenders participating would decrease.

The study involved the same group of participants that took part in the study published by Grubin, Madsen, Parsons, Sosnowski, and Warburg (2004). Fifty out of 116 solicited sex-offenders undergoing community-based treatment were subjected to two separate instances of polygraph testing (using the CQT), once at three months, the second time at six months. As described above, the offenders were split into "polygraph aware" and "polygraph unaware", and as mentioned previously, because of high rates of failure, all were informed of the second polygraph examination. The severity of behaviors admitted were rated on a scale between "low", "medium", and "high", based on the level of intent and effort one would have to put forth to commit them. The inter-rater reliability of these ratings was found to be approximately 0.8 . 
INTERVIEW OR INTERROGATION

What was observed after the first polygraph examination was a lack of significant difference between the two groups in terms of the severity of their admitted behavior, nor the quantity of its commission. At the second interview, after the two groups were both informed of impending second polygraph examination, there was a notable decrease in both the severity and frequency of high-risk behavior admitted by the participants. It was concluded that polygraph examination using the CQT could reduce both the number and the severity of the high-risk behaviors engaged in by sex offenders, but only after the sex offenders had experienced the polygraph exam for the first time.

Similar limitations that were speculated on in the previous research (Grubin et al., 2004) were brought up in this study as well, including the idea of appeasing treatment supervisors by falsely confessing to behaviors, but this was dismissed by citing an unpublished research article that estimated the likelihood of this to be very low. Additionally, the high participant dropout rate from the study, like the study mentioned above, severely limits the generalizability of the results obtained.

Between these two studies (i.e. Grubin et al., 2004; Madsen Parsons, \& Grubin, 2004) though, one crucial methodological flaw is present, and that is the utilization of the polygraph to validate itself. For example, as is mentioned in both studies, the high failure rates amongst both groups in the experiment on the polygraph examination, along with their equivalent quantities of new confessions, were viewed as substantial reasons to alter the procedure of the experiment. Additionally, when it was recorded that six of the participants made no new admissions to high-risk behavior, the researchers made comment that they had also passed their polygraph examinations. However, claiming that passing the polygraph exam helps to verify that the participants were truthful in their 
INTERVIEW OR INTERROGATION

supposed abstention from high-risk behavior is only as accurate as the polygraph itself, which (as abundantly noted), is a point of much disputation.

Sexual histories are considered important in the treatment of sexual offenders, however, getting a complete and honest record of past sexual offenses and deviant behavior can prove to be a challenge. Some proponents of post-conviction polygraph testing, however, believe it is a completely useful means of obtaining more thorough sexual and offense histories from offenders in treatment. Thus, a research study was conducted to test and observe the effect of polygraph testing on the disclosure of past offenses and other sexually deviant behaviors (Wilcox, \& Sosnowski, 2005). It was hypothesized that periodic polygraph testing would elicit further admissions to victims, occasions of sexually abusive behavior, and paraphilias previously than was previously known to treatment providers, as well as an earlier onset of sexual offending.

The study incorporated fourteen white, male sex offenders who were, at the time of the study, undergoing community-based treatment. All of the offenders participating in this study were rated as being medium to high risk, and had undergone at least 50 hours of treatment. Prior to examinations, the participants were instructed as to how the polygraph functioned, and how the physiological data collected from their interview could be used to detect deception in their responses. After their instruction, the offenders were subjected to a polygraph interview concerning their sexual and offense history.

As was expected by the researchers, when interviewed with the polygraph, participants admitted to more past victims and paraphilias than was previously known by their treatment providers. Additionally, a greater number of offenses, and a longer history of deviant behavior were derived from participant confessions. On an interesting note, it 
INTERVIEW OR INTERROGATION

was also observed that the participants displayed a relatively high level of crossover offenses (sexual offenses not directly related to the original offense they were convicted for). This contradicted a popular view in sex offender treatment, in which patterns of offense were considered concrete and relatively heterogeneous. It was thus concluded that polygraph testing could be useful in the obtaining and completion of a more thorough history of sexual and offense behavior.

Perhaps the most glaring weakness of the study was the small sample size. While the end sample size could have been attributed to participant dropout, but as mentioned in the procedure, only 25 offenders in treatment were solicited in the first place. Because of this notably small sample size, the generalizability of the results is somewhat questionable, though the rest of the study appears methodologically appropriate.

Finally, in regards to eliciting more forthright responses to treatment provider's questions, a study on a larger scale than any of the previous studies was carried out in order to evaluate the effectiveness of the polygraph in eliciting more forthright responses from sex offenders (Grubin, 2010). The study was commissioned by the National Probation Service as a larger scale version of a previous study (see Grubin et al., 2004) in order to test the value of post-conviction sex offender polygraph testing.

In this research study, 347 sex offenders from ten different probation areas in the United Kingdom volunteered to participate in periodic polygraph examinations regarding their past and current behavior. The participants were either already in community-based treatment, or were awaiting treatment. All participants were briefed on the function and purpose of the polygraph test before being asked to participate. In order to compare the effect of polygraph testing on disclosures of behavior, probation officers of a control 
INTERVIEW OR INTERROGATION

group of 308 sex offenders in four different probation areas were contacted regarding number of disclosures made by their wards.

The results of the study at hand were consistent with previous studies on the subject (i.e. Grubin et al., 2004; Madsen, Parsons, \& Grubin, 2004). After the first series of polygraph tests, $70 \%$ of case managers whose wards participated in the trial recorded new admissions from their participants, as opposed to only $14 \%$ from the control group. Overall, participants in the experiment who underwent polygraph testing were 14 times greater than their control counterparts. The severity, as reported by the caseworkers, of the new confessed behaviors, $63 \%$ were rated as "low", $27 \%$ as "medium", and $10 \%$ as "high". Finally, the probation officers of those who supervised the experimental group demonstrated a trend of rating their wards as higher risk than before, where as those who supervised the control group rated theirs as lower risk.

As opposed to the previous studies on the subject, the major strength to this study is its sample size. While the generalizability of the results obtained from the other investigations were compromised due to their relatively small sample sizes, the present study drew up a more than adequate sum of participants. However, as the researchers point out, the participants were not matched directly between experimental and control groups. This is particularly troubling, as it is difficult to speak to the effectiveness of polygraph on sex offenders when the population itself is so completely heterogeneous, composed of many different types of offenders (e.g. child molesters, rapists, voyeurs, exhibitionists, etc.). Additionally, the participants in the study were those offenders willing to attempt new forms of treatment, which could have suggested that these were 
INTERVIEW OR INTERROGATION

participants more motivated to not offend, or were possibly in treatment for longer/shorter periods of time.

With regards to the empirical research concerned with eliciting more forthright confessions from sex offenders, despite the methodological weaknesses of the present research, it would appear that post-conviction polygraphy demonstrates some promise. In all of the studies reviewed, it became apparent that polygraph testing shows some ability in extracting more complete, honest, and crucial information from offenders regarding high-risk behavior. However, what still has yet to be addressed is whether or not this information can actually be utilized in an effective manner. What's more, it is never clear as to what type of action, or repercussions, should result from these new revelations. It would almost seem as though post-conviction sex offender polygraphy in this capacity creates almost as much uncertainty as it dispels.

\section{Self-Report Studies}

Taking a different approach to evaluating the effectiveness of polygraphy in posconviction sex offender treatment, some researchers have turned to those being tested to determine the efficacy of the polygraph. Perhaps the most straightforward means of assessing the accuracy and usefulness of polygraph testing, it would seem a possible means of circumventing the conundrum of completely relying on the accuracy of the polygraph itself. Research following this notion appears to have found promising results for proponents, with sex offenders demonstrating generally optimistic views on its efficacy in their continued treatment.

A study conducted by Kokish, Levenson, and Blasingame (2005) sought to determine the accuracy and effectiveness of the polygraph in a post-conviction setting by 
INTERVIEW OR INTERROGATION

surveying participants following a polygraph interview. The sample for the study consisted of 95 sex offenders, all of whom were currently in community-based treatment programs, and had also received at least one polygraph examination.

The survey distributed to the participants included rudimentary questions such as how long the participants had been in treatment and how many polygraph exams they had taken part in. Other questions included how many times they had been rated as deceptive/truthful, whether they had ever gotten away with being deceptive ("false negative"), and whether they had been labeled as being deceptive while being truthful ("false positive"). Of those who had received false positives, participants were then asked when and how many times they had fabricated confessions in response to a false positive, and if these responses ever elicited any further false positives. Finally, and possibly the most important set of questions, the participants were asked whether or not they found the polygraph testing helpful in treatment, or if it posed the potential to compromise their therapy.

Results from the surveys seemed to display a relatively positive outlook on polygraph testing in a post-conviction context. Many $(n=68)$ participants found that the testing was beneficial to them not only in treatment by forcing them to be more honest, but that it also benefited them in their personal lives. Of the 95 participants, however, 18 claimed to have experienced a false positive, while 6 of them had claimed to be given a false negative. A few of the participants $(n=10)$ claimed that the polygraph testing was hampering their treatment by inducing anxiety and a negative outlook. Five participants reported creating fictitious admissions when faced with a false positive. 
INTERVIEW OR INTERROGATION

While it would appear that the sex offenders surveyed for this study demonstrated considerable support for the practice of post-conviction sex offender polygraphy, it is no minor point that some of the participants produced less than favorable results. When almost $25 \%$ of the participants claim to have been given erroneous results from their polygraph interviews, serious questions concerning the polygraph's accuracy, and consequently its validity, are raised. Not to be overlooked as well, is the threat of false confessions. While some would suggest that a rate of false confessions only slightly over $5 \%$ would not be enough to raise concern, a single false confession out of every 20 given is no small thing, especially when derived from such a controversial practice.

Perhaps the polygraph's effectiveness varies depending on the personality of those being interviewed. For instance, it could be possible that people more prone to nervousness or anger (emotions that may be associated with autonomic nervous system arousal) could be vulnerable to erroneous results. One recent study indicated that there is some truth to this idea (Grubin, \& Madsen, 2006). In this study, the efficacy and ethicality of post-conviction polygraph testing in Georgia sex offender rehabilitation programs were evaluated using participant-assessment surveys as well as personality inventories. Out of 321 sex offenders going through community-based treatment that were solicited by the researchers to participate, 176 agreed to complete a 12-item survey concerning previous experiences with the polygraph in a treatment setting. The offenders were predominately white males who had been convicted of contact offenses, the majority of which was child molestation. Participants were, in addition to the 12-item survey, asked to fill out a personality inventory, and take a rudimentary IQ test. 
INTERVIEW OR INTERROGATION

After all surveys were collected, the results indicated that the polygraph, according to participant responses on their experiences, had an approximate accuracy of $85 \%$, a false positive rate of $15 \%$, and a false negative rate of $16 \%$. Forty-four percent of the participants that completed the survey reported that they were more forthright with their treatment providers, and 34\% claimed to be more upfront with family and friends concerning their treatment. Concerning behaviors that would lead to recidivism, $56 \%$ of participants claimed that polygraph testing was "moderately to extremely helpful" in avoiding recidivating, $63 \%$ found it helpful in avoiding high-risk behaviors, and $67 \%$ that it was productive to their rehabilitation.

However, probably the most interesting product of the study were the observations made when comparing the results of the personality tests with those participants who claimed to have made false confessions when confronted with a false positive. When examined, it became apparent that those who claimed to have made false admissions scored exceptionally high on the neuroticism portion of the test, and lower on the conscientiousness section. This would appear to suggest that those sex offenders who demonstrated elevated levels of anxiety and lower levels of self-control/constraint were more likely to make false confessions of deviant/high-risk behavior when confronted with a false positive.

These studies have presented some interesting points to the discussion of both efficacy and ethicality with concerns to post-conviction polygraph testing amongst sex offenders. Primarily, it would appear as though sex offenders, on the whole, endorse the utilization of polygraph testing in their rehabilitation. What's more, it is even suggested by the offenders that the polygraph is useful in preventing them from reoffending. 
INTERVIEW OR INTERROGATION

However, as is typically the problem with survey-style research, the data collected from the participants is impossible to verify. Survey results can't be matched to any one individual due to their anonymous nature, nor can polygraph results be matched to any survey. This issue is made all the more complex when one considers that while participant truthfulness is never entirely certain for any survey study, the genuineness of the answers collected in these research studies are even more questionable due to the typically deceptive nature of the population from which these samples were drawn.

\section{Bogus Pipeline}

Proponents of post-conviction sex offender polygraph testing claim that despite the questionable accuracy of the polygraph itself, the more imperative purpose it serves is to prevent high-risk behavior and to elicit more complete and honest answers from the offenders (Grubin, 2008; Grubin, 2010). However, if this is the case, is it really necessary to use a real polygraph and a certified examiner? Couldn't a fake polygraph be used, and the sex offender simply told that it is highly accurate and valid?

These questions, in part, were addressed in recent research into what has been dubbed the "Bogus Pipeline", i.e. a fake lie detector, and its ability to elicit more sincere information from sex offenders, namely child molesters. The term "bogus pipeline" refers to idea that making false claims about the ability to detect deception will elicit more truthful responses from an interviewee, in this case, from sex offenders hooked up to a fake lie detector (Gannon, 2006). However, the only way in which the bogus pipeline works is if the person hooked to it believes in its accuracy and ability to detect deception.

The bogus pipeline's ability to elicit more sincere responses from interfamilial child molesters was demonstrated in an experimental study performed by Theresa 
INTERVIEW OR INTERROGATION

Gannon (2006). In the experiment, Gannon sought to test the effect of a bogus lie detector on its ability to extract endorsements of cognitive distortions from child molesters, as well as its affect on impression management. It was discovered that the bogus pipeline appeared to have no significant effect on the degree of impression management exhibited by the child molesters, and even decreased the display of cognitive distortions. These results were surprising to the researcher, especially due to the fact that most participants $(85 \%)$ believed that the bogus pipeline could detect deception.

The observations made during the experiment led to the conclusion that child molesters didn't hold as many cognitive distortions as was previously believed in literature. However, these conclusions were contradicted in a recreation of Gannon's experiment by Gannon, Keown, and Polaschek (2007). In their study, just as in the previous experiment, the effect of a fake lie detector ("bogus pipeline") on the endorsement of cognitive distortions and impression management was measured using several survey techniques. Unlike the first experiment, however, the researchers observed a significant increase in cognitive distortion endorsements and impression management in the group that was subjected to the bogus pipeline than those that were not.

Like most of the previous research done with child molesters, and sex offenders in general, the major weakness in both of these studies was the small sample sizes $(n=32$ and $n=41$ respectively). Perhaps the most glaring weakness, more in the first study, was that the level of belief in the bogus pipeline was truly unverifiable. While it would be simple to take participants' reported belief in the bogus pipeline at face value, it may be possible that participants claimed to believe the accuracy of the bogus pipeline simply because they had no discernable reason to openly refute it. This does not necessarily 
INTERVIEW OR INTERROGATION

mean, though, that participants truly believed it could detect lies, but merely that participants had no concrete reason to doubt it.

Perhaps the main reason why the bogus pipeline research fits into this review is the fact that one of the major points of the bogus pipeline, giving examinees incentive to be more honest, is one of the major selling points for proponents of post-conviction sex offender polygraph testing (Grubin, 2008; Grubin, 2010). However, as can be seen simply between these two studies following similar procedures, there's little consensus on what a supposedly "accurate" lie detector can elicit. More importantly though, as pointed out in the latter study (Gannon, Keown, \& Polaschek, 2007), the clinical value of the distortions uncovered is relatively unknown. It is worth noting that this level of discrepancy between the two studies is over a single group of sex offenders (child molesters), which, in and of themselves, are a fairly heterogeneous group, let alone over sex offenders as a whole.

\section{Recidivism Prevention}

Up until now in this review, the majority of contemporary literature on the subject of post-conviction sex offender polygraph testing has been focused on either information gathering (including the bogus pipeline technique), or relying on surveys of how sex offenders feel about polygraph testing. While these techniques may be able to elicit information considered important in sex offender management (e.g. sexual and criminal history, paraphilias, cognitive distortions, etc.), the single most important question in regards to sex offender management and treatment, and the soul reason for it, has largely gone unaddressed: Does post-conviction polygraph testing prevent sex offenders from recidivating? In essence, the question of whether or not polygraph testing can truly keep 
INTERVIEW OR INTERROGATION

sex offenders from criminally re-offending has been somewhat neglected in contemporary research.

The only article from the past decade that could be found for this review was a study analyzing the re-offense rates of polygraphed sex offenders versus those of nonpolygraphed offenders (McGrath, Cumming, Hoke, \& Bonn-Miller, 2007). Researchers cited the statements made by proponents of the polygraph concerning the polygraph's ability to not only elicit more honest answers to questions concerning high-risk behavior, but also to act as a deterrent to sex offender recidivism.

The study focused on two matched groups of 104 sex offenders undergoing community-based treatment in the state of Vermont. Participants were undergoing treatment through the Vermont Treatment Program for Sexual Abusers, which at the time was undergoing trials of post-conviction polygraph testing. The participants in both groups of 104 were matched in terms of Static-99 score, completion of prison-based treatment, and date of community reintegration. However, one of the groups of offenders were in treatment groups that incorporated periodic polygraph testing into the normal group cognitive behavioral treatment. It was hypothesized by the researchers that the group that had had polygraph testing would not only disclose more high risk behaviors to treatment providers, but also would demonstrate a lower recidivism rate after five years than those the group that did not undergo polygraph testing.

Sex offender participants in the polygraph group were subjected to an average of 2.2 polygraph examinations during the 49 -month period of the experiment. During these exams, in $68.7 \%$ of the exams, no deception was detected, $20 \%$ percent resulted in deception being detected, and $9.1 \%$ were found to be inconclusive. The remaining $2.2 \%$ 
INTERVIEW OR INTERROGATION

of the polygraph exams were discontinued mid-interview. Concerning the results of the experiment, the researchers noted that of the high-risk behaviors admitted by the sex offenders during polygraph interviewing, $60-80 \%$ were previously unknown to case workers or treatment providers. Between treatment providers and probation officers, both (96\%) found the information provided through the polygraph interviews to be helpful, though probation officers rated the polygraph as significantly more helpful than treatment providers.

When the actual rates of recidivism were measured, the only significant difference in re-offense rates between the polygraph and non-polygraph groups was for offenses categorized as violent nonsexual. Participants in the polygraph group demonstrated, approximately, a $2.9 \%$ rate of recidivism, whereas the non-polygraph group recidivated at a rate of approximately $11.5 \%$. However, when comparing the two groups rates for other offenses, such as violent sexual offenses, nonviolent sexual offenses, or other general offenses, no significant differences were found.

\section{Summary}

In short, the current state of the empirical research concerning post-conviction sex offender polygraph testing is at best worthy of cautious optimism, and at worst, indirect and inconclusive. The studies that focus on the polygraph's ability to elicit more complete and forthright information (Grubin et al., 2004; Madsen Parsons, \& Grubin, 2004; Wilcox, \& Sosnowski, 2005; Grubin, 2010) from sex offenders demonstrate a marked increase in the number and severity of the high-risk behaviors the interviewees have engaged in, but suffer from numerous methodological weaknesses. With regards to the bogus pipeline research (Gannon, 2006; Gannon, Keown, \& Polaschek, 2007), the 
INTERVIEW OR INTERROGATION

inconsistent and methodologically unsound results produced by the contemporary

literature also raise doubt in the polygraph's efficacy in a post conviction setting, and also bring up an important concern. If the effect of the polygraph lies more in its ability to give offenders more incentive to be honest during rehabilitation, what would happen to its efficacy if offenders no longer believed in its accuracy?

Lastly, the only real study that spoke towards the ability of the polygraph to curb recidivistic behavior in sex offenders (McGrath, Cumming, Hoke, \& Bonn-Miller, 2007), the whole purpose behind sex offender rehabilitation, reported fairly underwhelming results. Because of the fact that periodic polygraph testing only reduced violent, nonsexual recidivism amongst sex offenders not only speaks little to its ability to curb recidivism in general, but also questions its need to be specifically applied in sex offender rehabilitation.

\section{Theoretical and Methodological Literature}

Not all of the published literature on post-conviction polygraph testing relies on empirical research. Some researchers have taken to making arguments as to the efficacy and ethicality of polygraphy through discussion of methodological and theoretical points (e.g. Grubin, 2008; Cross, \& Saxe, 2001). While these articles may not provide tangible, concrete evidence as to whether the practice of post-conviction sex offender polygraph testing is effective or not, it does aid in the clarification and definition of the boundaries and ethics that constitute the field of forensic psychology.

\section{Literature in Support of Polygraphy}

While a major contributor to the empirical research of post-conviction sex offender polygraph testing, Grubin (2008) wrote an article in order to respond to 
INTERVIEW OR INTERROGATION

naysayers on the subject, even addressing some of them by name (e.g. Ben-Shakhar, 2008). Specifically, Grubin addresses the oft-made criticisms of the polygraph concerned with the format of the tests in question, their accuracy, and the ethicality of their practice, claiming the source of them to be confusion and misinformation.

In order to speak to the claims made by critics concerning the efficacy and accuracy of the polygraph, Grubin cited studies reporting the accuracy of the polygraph to detect deception in interviewees to be between $80-90 \%$, which he corroborates with studies that focused on sex offender surveys. According to Grubin, these findings demonstrate that the accuracy of the polygraph examinations were high enough to correlate the measures of the test with the detection of deception. This correlation is made even stronger, according to the article, with a population that expresses high rates of duplicity, such as sex offenders. Furthermore, in regards to rates false confessions, Grubin indicates that at a rate estimated at $10 \%$, false confessions are a real, but unimportant problem. Finally, in regards to countermeasures, Grubin argues that while it is very possible for offenders to obtain techniques to "beat" the polygraph, it requires polygraph feedback (which he claims offenders do not have easy access to) in order to utilize these countermeasures effectively,

Grubin also speaks towards ethical concerns of the polygraph as well, especially with regard towards the suggestions by opponents that polygraphy is a coercive means of attaining information. Firstly, Grubin distinguishes post-conviction sex offender polygraph testing from investigative polygraphy, in that the post-conviction application is a routine interview rather than an interrogation, with no negative repercussions for confessions made during the polygraph itself. Moreover, the polygraph is seen to be used 
INTERVIEW OR INTERROGATION

to "enhance" the disclosure of information deemed necessary for treatment and management, not as a means of bringing negative sanctions against offenders for failing the exam.

Responding to critics' claims that the polygraph testing is a means of psychologically manipulating offenders by convincing them that the polygraph is much more accurate than it is (the "bogus pipeline"), Grubin admits that while that may happen, it is unethical and unnecessary. In fact, Grubin states that the bogus pipeline theory is insufficient to explain increased rates of confession during polygraph testing, as the majority of confessions are made after a failed exam. However, Grubin does agree that participants should be informed about the statistics of the polygraph, but disagrees with the idea that informed consent should be received before requiring offenders to submit to polygraph interviews. He argues that in a post-conviction setting, as a condition of parole or probation, offenders are subjected to a number of restrictions, penalties and stipulations that would be deemed immoral in any other setting. Thus, the coercive elements of the polygraph exam, according to Grubin, should pose no problem, given the context in which it is administered.

\section{Literature Concerned or in Opposition of Polygraphy}

More than a decade ago, Cross and Saxe (2001) wrote an article in an attempt to draw attention to the widespread use of polygraph testing in post-conviction sex offender management and treatment. In particular, Cross and Saxe expressed the concern that the only researchers looking into its application in the post-conviction setting were those that had already taken an affirmative stance on polygraph testing. 
INTERVIEW OR INTERROGATION

Another point of concern, according to Cross and Saxe, is that despite the polygraph's widespread application, there was little in the way of definitive research that demonstrated the efficacy of polygraph testing in a sex offender treatment and management setting. In fact, they pointed out that there was little to no research into possible adverse effects of regular polygraph testing in a post-conviction setting, nor any research into the effect of different psychological stimuli on physiological responses related to the test. Ultimately, Cross and Saxe refrained from outright condemning postconviction polygraph testing, but cautioned against its widespread use, as there was little in the way of actual empirical research concerning benefits or detriments, nor was there even a disciplinary consensus on its validity or ethicality.

While polygraph testing has been widespread in the United States, its increasing use in treatment programs outside of the U.S.A. has caused several professionals a great deal of concern. Meijer, Verschuere, Merckelbach, and Crombez (2008) sought to review the literature of the CQT in post-conviction sex offender polygraph testing in order to highlight their concerns with its increasing utilization across the globe. In their review, Meijer et al. criticize the lack of literature speaking to the accuracy of post-conviction sex offender polygraph testing. According to the researchers, the theory suggesting that the polygraph's utility in eliciting confessions is more important than the test's accuracy not only denotes as a non-diagnostic exam, but the increased rate of confessions could more than likely be attributed to the polygraph's intimidation factor.

On top of this, there is no conclusive evidence to suggest that the polygraph is effect as a deterrent to recidivism, despite proponents claims that the polygraph is to postconviction sex offenders as urine analysis is to recovering drug addicts. Meijer et al. 
INTERVIEW OR INTERROGATION

conclude that proponents of post-conviction polygraph testing hold unrealistic and unfounded faith in the polygraph, and that their hubris could potentially cause harm to both the sex offenders, and those who they may potentially offend against.

Possibly one of the most outspoken opponents of the CQT, Ben-Shakhar (2008), at the same time as Grubin (2008), published his scathing review of the practice of postconviction polygraph testing. In it, Ben-Shakhar attacks both the unscientific nature of the CQT, but also its ability to treat and manage sex offenders. Firstly, it is claimed in the article that not only is the CQT not a standardized test in the technical definition, but that it is highly subjective. Ben-Shakhar points out that the physiological responses of interviewees is compared to a baseline of control questions asked in a pre-test interview, and based on the interpretation of these non-quantified measures, the interviewer is to extrapolate whether the interviewee is being deceptive or not. These conclusions, it is suggested, can easily be affected by unintentional (or intentional) bias from the examiner based on prior knowledge of the interviewee (offense history, background information), how the interviewer presents the questions, or even simply knowing that the interviewee is a convicted sex offender.

Speaking of efficacy, Ben-Shakhar, as has been apparent to many other detractors, pointed out that not only is there a poor collection of literature which demonstrates the ability of the polygraph to prevent sex offenders from re-offending, but that the literature on sex offender polygraphy in general suffers from poor sampling techniques. In the modern era, information concerning polygraphy and countermeasures are also readily available. Based on this, Ben-Shakhar also argues that the CQT quickly loses its effectiveness as both a means of extracting information, and a recidivism deterrent to sex 
INTERVIEW OR INTERROGATION

offenders. It is with these points in mind that the article condemns the CQT as an ineffective means of facilitating sex offender rehabilitation and management.

Ethics are an important consideration in the appropriateness and morality of a possible form of treatment, and in no area of forensic psychology is that truer than in post-conviction sex offender polygraph testing. Vess (2010) acknowledges polygraph as a possible route to treating sex offenders, but presents several serious points of ethical concern. Firstly, Vess insists that despite proponent claims, the accuracy of the polygraph in intrinsically tied to the ethicality of the examination process, and that its continued implementation into sex offender management and treatment is possibly just an attempt to lend the polygraph exam scientific credibility.

Secondly, for the polygraph to be ethical, practitioners must be completely honest and straightforward with regards to the accuracy of the polygraph, as well as the practices implemented in the examination. After all, if deceiving the offenders being treated is necessary for the "successful" implementation of post-conviction polygraph examination, then the practice is more than likely lacking in ethical soundness.

Many researchers have focused on the polygraph in terms of its ability to manage adult sex offenders, but what about the issue of juvenile sex offenders and postconviction polygraph testing? Juveniles are largely regarded in the psychological community as a particularly vulnerable population, and the fact $50 \%$ of juvenile sex offender treatment programs require periodic polygraph testing (a practice not found in other areas of juvenile justice programs) means that even more care must be taken in order to ensure that no breach of ethics is being made (Chaffin, 2010). Labeling the polygraph as an interrogative technique, Chaffin proclaims that the polygraph and the 
INTERVIEW OR INTERROGATION

tests designed around it are coercive techniques, as the interviewee gives the confessions elicited from them unwillingly. Being a coercive technique, it is thus possible that forcing juveniles to submit to post-conviction polygraph testing in the absence of any research concerning its affects on juvenile sex offenders could, at the very worst, be violating the ethical element of non-maleficence, or at least lack any sort of beneficence.

While it is necessary to consider both the safety and ethical treatment of both the offender and the community, and while it is possible that polygraph examination of juvenile sex offenders may be beneficial, there is no definitive evidence to suggest what sort of effect it really has on juvenile sex offenders. This uncertainty not only leaves a hole in the literature concerning post-conviction sex offender polygraph testing, but also an ethical grey area which treatment providers should tread with care.

\section{Review}

\section{Limitations and Gaps in the Literature}

When examining the empirical literature, the most obvious weakness in the design of the experiment is the generally paltry sample sizes. Aside from three of the studies examined in this review (Grubin, 2010; Grubin, \& Madsen, 2006; McGrath, Cumming, Hoke, \& Bonn-Miller, 2007), all of the studies focused were conducted with sample sizes well under 100 participants, one of which utilized as few as 14 subjects (Wilcox, \& Sosnowski, 2005). These relatively small sample sizes, coupled with the high dropout rate of many of the studies, can not only call into question the value and validity of the results from these studies, but also severely limit their generalizability. Generalizability of one's results is universally important in area of forensic psychology, but even more so 
INTERVIEW OR INTERROGATION

when dealing with a population as heterogeneous as sex offenders (child molesters, rapists, voyeurs, exhibitionists, etc.).

The issue of heterogeneity brings up one crucial gap in the contemporary literature as it stands, which is whether or not different groups of sex offenders would respond differently to post-conviction polygraph testing. While Gannon (2007) focused exclusively on child molesters, and her results appeared somewhat similar to those found by Grubin et al. (2004), the fact of the matter is that different categories of sex offenders typically express varied psychological traits compared to others.

For example, child molesters tend to exhibit behavior in line with neuroticism (external locus of control, high levels of anxiety) (Marziano, Ward, Beech \& Pattison, 2006), which, as pointed out by Grubin and Madsen (2006), is a personality trait common amongst those claiming to have made false confessions when faced with a false-positive. Rapists, additionally, generally exhibit psychopathic and sadistic tendencies (Brown, \& Forth, 1997), which could affect their physiological responses towards deception. In fact, concerning psychopathic sex offenders, one study has shown that male psychopaths' hindered adrenergic system appears to lower the accuracy of the polygraph during interviews (Verschuere, Crombez, Clercq, \& Koster, 2005).

In regards to literature that utilizes self-report surveys, a few methodological concerns arise. A major drawback to this method, as it is with any form of survey-based research, is that there is almost no way to verify that the information being given is, in fact, truthful. It could be possible that sex offenders who reported the polygraph being accurate were simply trying to give favorable responses to the surveys, perhaps because they felt it was what they were expected to respond, or perhaps they truly wanted to 
INTERVIEW OR INTERROGATION

believe that the treatment was helping them. Unfortunately, there is no reliable way to verify this, save for some sort of fictional "truth finder".

Additionally, in regards to unverifiable phenomena, the issue of false-positives, despite what is stated by Grubin (2008), is quite a serious matter. Its seriousness stems partly from the fact that little in the way of research has been conducted in order to assess whether false-positives can adversely affect therapy and rehabilitation for sex offenders. Because autonomic nervous system arousal is not exclusive to deception, it is possible that "positive" readings are psychological responses to interview questions other than being deceptive, such as anxiety, or anger. In fact, one possible idea that has not received much in the way of attention, especially with such a sexually motivated population, is the notion that certain interview questions may trigger sexual arousal in interviewees, thus causing a potentially false positive on the polygraph. Sexual arousal is characterized, partially, by an increase in blood pressure and breath rate, both of which are measured by the polygraph. Coincidentally, with so many questions regarding past, and potentially recent sexual offenses, it is all too possible that the interview drums up deviant sexual memories, and could just as potentially cause a positive reading on the polygraph.

However, possibly the most glaring gap in the literature as it stands is deficiency on experimental and research studies monitoring the effect of post-conviction polygraph testing on rates of recidivism amongst sex offenders. Amongst contemporary literature on the subject of post-conviction polygraph testing, only one article was found that sought to monitor this connection (McGrath, Cumming, Hoke, \& Bonn-Miller, 2007). While the article was fairly thorough, a single study is hardly enough to confirm the effect of (as can be seen from the literature) an incredibly controversial treatment method. For any 
INTERVIEW OR INTERROGATION

method of treatment designed for a criminal population, the fact of whether or not reduces rates of recidivism is of utmost importance. This fact, however, remains to be reaffirmed in contemporary research.

\section{Future Directions}

Being a relatively underdeveloped field of research, there are still many directions that remain unexplored in the area of post-conviction sex offender polygraphy. As stated above, the most pertinent and crucial question of sex offender polygraphy that must be answered is whether or not it actually aids in the reduction of rates of recidivism. While it is comforting to note that polygraphy elicits more confessions out of sex offenders concerning deviant behavior, and while it may seem pleasing to note that a goodly number of the sex offenders themselves approve of the polygraph in its current application, it hardly proves whether or not it is an effective technique.

In this vein, it is suggested that current research should turn its attention towards longitudinal studies examining the polygraph and its effect on rates of re-offending. Specifically, studies should focus on at least the first five years following the release of the sex offender from incarceration, as this is largely viewed as the period in which sex offenders are most likely to recidivate (Zgoba \& Levenson, 2008).

Another area that is in dire need consideration from an ethical standpoint is whether or not the polygraph could pose any harm to those forced to submit to it. As practitioners and therapists, the chief concern for any psychologist, even those in a forensic setting, must be nonmaleficence. However, as pointed out by several of the authors reviewed above (e.g. Ben-Shakhar, 2008; Chaffin, 2010, Vess, 2010), little is known about how periodic polygraph testing and related phenomena (false-positives, 
INTERVIEW OR INTERROGATION

confrontational interviewing, etc.) can affect the "typical" sex offender, let alone high risk populations such as juveniles and those with developmental disabilities.

Other physiological tests may be able to answer one small question regarding false positive readings derived from post-conviction polygraph interviews. The penile plethysmograph is a device used to measure swelling and blood flow in the penis of male subjects, the results of which are often interpreted to indicate levels of sexual arousal (somewhat in the same way the polygraph detects deception). Using the plethysmograph in concert with the polygraph, it could be tested whether or not interview questions during a polygraph exam elicit sexual arousal from sex offenders. Exploring this avenue could potentially address one possible explanation concerning false positive results obtained from an interview, and could help address future methodological issues that could arise.

Also mentioned above, the issue of heterogeneity amongst sex offenders poses an interesting avenue of research. Specifically, it would of some import to explore whether the polygraph expresses higher levels of efficacy amongst different groups of sex offenders (e.g. rapists, child molesters, exhibitionists, etc.). Contemporary postconviction treatment programs for sex offenders often utilize group, "one-size-fits-all” styles of therapy, often mixing different groups of offenders together in rehabilitation. Whether or not this proposed means of treatment works well for a broad, diverse population (i.e. sex offenders) remains to be seen. 
INTERVIEW OR INTERROGATION

\section{Closing Statements}

The purpose of this review was to take inventory and analyze the current pool of literature surrounding the topic of the efficacy and ethicality of post-conviction sex offender polygraph testing. This was seen as necessary due to the fact that not only is polygraph in a post-conviction setting already widespread and continuing to grow in popularity, but also because there is still a great deal of debate and contention regarding its usefulness. In summary, it must be stated that while there is no definitive evidence disproving or discrediting the polygraph in post-conviction sex offender management and rehabilitation, similarly, there is no clear and convincing evidence suggested it is useful or effective.

The majority of the empirical research succeeds in highlighting the effects of the polygraph on issues related to rehabilitation and management (i.e. increasing confessions and apparently more honest answers), but failed to attack the key question itself: Does periodic polygraph testing reduce rates of recidivism amongst sex offenders? Moreover, the only article found that did address this question (McGrath, Cumming, Hoke, \& BonnMiller, 2007) produced lukewarm results in regards to the efficacy of post-conviction sex offender polygraph testing, at least in its specific application to treating sex offenders.

Regarding ethicality, the polygraph and its post-conviction application is fraught with dangerous grey areas. Firstly, as noted above, there is no definitive evidence, nor any disciplinary consensus as to the efficacy of the polygraph, or its use in postconviction sex offender treatment. In order for a treatment to be ethical, it must first be demonstrated, through strenuous and judicious research, to be more effective than doing nothing, that it have the same effect for similar patients, it should pose a benefit towards 
INTERVIEW OR INTERROGATION

those being subjected to it, and that there is a consensus amongst professionals in the relevent (American Psychological Association, 2002). So far, none of these criterions have been completely and unambiguously met. The issue of efficacy has already been addressed, and the benefits to those participating in the study have currently only been ascertained by asking the offenders themselves (other than looking at rates of recidivism), which is shaky evidence at best, as the whole reason the offenders are being polygraphed is because they, as a population, exhibit high levels of deception. Speaking of populations, it is unclear if the criterion of consistency between similar patients is far from having been met, as both the generalizability of the studies reviewed were quite questionable, either through small sample sizes, unmatched experimental and control groups, or by simply treating sex offenders as a homogenous population.

With regards for a disciplinary consensus, it could safely be said that there really is none. A lack of any definitive evidence as to efficacy has lead to much open debate as to the interpretation of the data. On top of this, a lack of a properly defined procedures and standardization of polygraph results makes it difficult for specialists to make heads or tails of the objective results, if there even is such a thing when it comes to the polygraph.

Finally, it is wholly unethical for the polygraph to be utilized when its potential effects are relatively unknown. It is both irresponsible and dangerous if there is no information available on whether or not the treatment being administered has the potential to cause psychological harm. This is especially true when administered on potentially vulnerable populations (i.e. juveniles and the developmentally/cognitively disabled). Some may argue that when dealing with a criminal population, the ethical 
INTERVIEW OR INTERROGATION

concerns are somewhat lessened, but this is only valid when the potential beneficence outweighs the potential harm, both of which are relatively unknown.

Treating and managing recovering sex offenders can often be a monumental task, and it can seem frustrating to have the very patients one is charged with rehabilitating actively deceive, or fall to re-offending. However, it is important to keep in mind that as scientific practitioners, forensic psychologist must ensure that the methods they utilize are not only ethically sound, but that it actually works. Suffice to say that condoning and utilizing post-conviction sex offender polygraph testing on such a wide scale is a betrayal to both duties that each forensic psychologist is responsible for.

Is this to say that post-conviction sex offender polygraph testing should be completely abandoned? The answer, in short, is a hesitant "no". By no means should psychology throw the proverbial baby out with the bathwater, but first we should make sure the kid is even in the tub. It is well within the realm of possibility that postconviction sex offender polygraph testing has the potential to improve sex offender management and rehabilitation. After all, the studies on eliciting more forthright information from sex offenders have been fairly promising (e.g. Grubin, 2010; Grubin, Madsen, Parsons, Sosnowski, \& Warberg, 2004; Kokish, Levenson, \& Blasingame, 2005).

However, the fact that it has not only been endorsed and even, in some cases, mandated via legislation and judicial decree shows a deep schism in the discipline between the scientific and clinical nature of psychology, and the dichotomous need for truth and punishment of the criminal justice system. Until more information is available as to the effects of post-conviction sex offender polygraph testing, psychologists should 
INTERVIEW OR INTERROGATION

only ever utilize it in a research capacity, and not on such a global scale as it seems to

have found itself in. After all, forensic psychologists should focus on rehabilitation and evaluation, and leave the interrogation to law enforcement officials. 
INTERVIEW OR INTERROGATION

References

Ben-Shakhar, G. (2008). The case against the use of polygraph examinations to monitor post-conviction sex offenders. Legal and Criminological Psychology, 13, 191207. doi: 10.1348/135532508X298577

Ben-Shakhar, G., Har-Hillel, M., \& Kremnitzer, M. (2002). Trial by Polygraph: Reconsidering the Use of the Guilty Knowledge Test in Court. Law and Human Behavior, 26(5), 527-541.

Ben-Shakhar, G., \& Elaad, E. (2003). The Validity of Psychophysiological Detection Information With the Guilty Knowledge Test: A Meta-Analytic Review. Journal of Applied Psychology, 88(1), 131-151. doi: 10.1037/0021-9010.88.1.131

Brown, S. L., \& Forth, A. E. (1997). Psychopathy and sexual assault: Static risk factors, emotional precursors, and rapist subtypes. Journal of Counseling and Clinical Psychology, 65, 848-857.

Chaffin, M. (2011). The Case of Juvenile Polygraphy as a Clinical Ethics Dilemma. Sexual Abuse: A Journal of Research and Treatment, 23(3), 314-328. doi: $10.1177 / 1079063210382046$

Cross, T. P., \& Saxe, L. (2001). Polygraph Testing and Sexual Abuse: The Lure of the Magic Lasso. Child Maltreatment, 6(3), 195-206.

Emerick, R. L., \& Dutton, W. A. (1993). The Effect of Polygraphy On the Self Report of Adolescent Sex Offenders: Implications for Risk Assessment. Annals of Sex Research, 6(2), 83-103. 
INTERVIEW OR INTERROGATION

Furedy, J. J. (1996) The North American polygraph and psychophysiology: disinterested, uninterested and interested perspectives. International Journal of Psychophysiology, 21, 97-105.

Gannon, T. A., Keown, K., \& Polaschek, D. L. L. (2007). Increasing Responding on Cognitive Distortions in Child Molesters: The Bogus Pipeline Revisited. Sex Abuse, 19(1), 5-22. doi: 10.1007/s11194-006-9033-0

Gannon, T. A. (2006). Increasing Honest Responding on Cognitive Distortions in Child Molesters : The Bogus Pipeline Procedure. Journal of Interpersonal Violence, 21(3), 358-375.

Grubin, D. (2010). A Trial of Voluntary Polygraph Testing in 10 English Probation Areas. Sexual Abuse: A Journal of Research and Treatment, 22(3) 266-278. doi: $10.1177 / 1079063210369012$

Grubin, D. (2008). The case for polygraph testing of sex offenders. Legal and Criminological Psychology, 13, 177-189. doi: 10.1348/135532508X295165.

Grubin, D. (2010). The Polygraph and Forensic Psychiatry. The Journal of the American Academy of Psychiatry and Law, 38, 446-451.

Grubin, D., \& Madsen, L. (2006). Accuracy and utility of post-conviction polygraph testing of sex offenders. The British Journal of Psychiatry, 188, 479-483. doi: 10.1192/bjp.bp.105.008953

Grubin, D., Madsen, L., Parsons, S., Sosnowski, D., \& Warberg, B. (2004). A Prospective Study of the Impact of Polygraphy on High-Risk Behaviors in Adult Sex Offenders. Sexual Abuse: A Journal of Research and Treatment, 16(3), 209222. doi: 
INTERVIEW OR INTERROGATION

Kokish, R., Levenson, J. S., \& Blasingame, G. D. (2005). Post-conviction Sex Offender Polygraph Examination: Client-Reported Perceptions of Utility and Accuracy. Sexual Abuse: A Journal of Research and Treatment, 17(2), 211-221. doi: $10.1177 / 107906320501700210$

Letourneau, E. J., \& Miner, M. H. (2005). Juvenile Sex Offenders: A Case Against the Legal and Clinical Status Quo. Sexual Abuse: A Journal of Research and Treatment, 17(3), 293-312.

Madsen, L., Parsons, S., \& Grubin, D. (2004). A preliminary study of the contribution of periodic polygraph testing to the treatment and supervision of sex offenders. The Journal of Forensic Psychiatry \& Psychology, 15(4), 682-695. doi: $10.1080 / 1478994042000270256$

Marziano, V., Ward, T., Beech, A. B., \& Pattison, P. (2006). Identification of five fundamental implicit theories underlying cognitive distortions in child abusers: A preliminary study. Psychology, Crime \& Law, 12(1), 97-105. doi: $10.1080 / 10683160500056887$

McGrath, R. J., Cumming, G. F., Hoke, S. E., \& Bonn-Miller, M. O. (2007). Outcomes in a Community Sex Offender Treatment Program: A Comparison Between Polygraphed and Matched Non-Polygraphed Offenders. Sex Abuse, 19(1), 381393. doi: $10.1177 / 107906320701900404$

Meijer, E. H., Verschuere, B., Merckelbach, H. L. G. J., \& Crombez, G. (2008). Sex offender management using the polygraph: A critical review. International Journal of Law and Psychiatry, 31, 423-429. doi: 10.1016/j.ijlp.2008.08.007 
INTERVIEW OR INTERROGATION

Verschuere, B., Crombez, G., De Clercq, A., \& Koster, E. H. W. (2005). Psychopathic traits and autonomic responding to concealed information in a prison sample. Psychophysiology, 42(2), 239-245.

Vess, J. (2011). Ethical Practice in Sex Offender Assessment: Consideration of Actuarial and Polygraph Methods. Sexual Abuse: A Journal of Research and Treatment, 23(3), 381-396. doi: 10.1177/1079063210382045

Wilcox, D. T., \& Sosnowski, D. E. (2005). Polygraph examination of British sexual offenders: A pilot study on sexual history disclosure testing. Journal of Sexual Aggression, 11(1), 3-25. doi: 10.1080/13552600410001667797

Zgoba, K. M., \& Levenson, J. (2008). Variations in the Recidivism of Treated and Nontreated Sexual Offenders in New Jersey: An Examination of Tree Time Frames. Victims and Offenders, 3, 10-30. doi: 10.1080/15564880701751639 